\title{
Prevalence and knowledge of carpal tunnel syndrome among the dental practitioners; survey based study in Riyadh
}

\author{
Dr. Anfal AlAnazi ${ }^{1 *}$, Dr. Lujain AlZahrani ${ }^{2}$, Dr.Heba Alshammary ${ }^{3}$, Dr.Nadeen AlMaghamsi ${ }^{4}$, \\ Dr.Saja Alobaidi ${ }^{5}$, Dr.Shahzeb Ansari ${ }^{6}$ \\ ${ }^{1}$ BDS, Dental intern, College of Dentistry, Riyadh Elm University, Saudi Arabia \\ ${ }^{2}$ BDS, Dental intern, College of Dentistry, Riyadh Elm University, Saudi Arabia \\ ${ }^{3}$ BDS, Dental intern, College of Dentistry, Riyadh Elm University, Saudi Arabia \\ ${ }^{4} B D S$, Dental intern, College of Dentistry, Riyadh Elm University, Saudi Arabia \\ ${ }^{5}$ BDS, Dental intern, College of Dentistry, Riyadh Elm University, Saudi Arabia \\ ${ }^{6}$ BDS, Lecturer Preventive Dentistry, Preventive Department, College of Dentistry, Riyadh Elm University, Saudi Arabia \\ *Corresponding author E-mail:Heba.fahad@gmail.com
}

\begin{abstract}
Carpal Tunnel Syndrome (CTS) is a common medical condition that results in numbness, pain and tingling in the arm and constitutes about $90 \%$ of neuropathy entrapments. The condition arises when the median nerve in the arm is compressed. CTS can degenerate rapidly to cause nerve damage. The effects of CTS on medical practitioners can be serious given the speculation that the condition is work-related. Consequently, this study seeks to establish the prevalence and knowledge of CTS among dental practitioners in the city of Riyadh. In doing so, the research attempts to find relationships between CTS and workload and the experience of the dental practitioners. The study takes the model of sectional study that targets dental practitioners specifically in the city of Riyadh. The researchers recruited 190 dentists and used google forms to collect data from the respondents. The questions in the survey related to symptoms of the condition and the related demographics. The study found a significant comparison of the prevalence and knowledge of CTS among various subgroups. Daily patient exposure and work experience were some of the underlying features discovered in the study. Dentists with more work experience demonstrated significant knowledge on the condition and registered an equally high prevalence of pain associated with CST. The findings of the research show a direct correlation between workload, work experience, and CST.
\end{abstract}

Keywords: Knowledge; Carpal Tunnel; Syndrome; Diagnosis; Disease.

\section{Introduction}

The Carpel Tunnel Syndrome (CTS) was first studied and discovered in 1854 in Pagel. It still remains confusing and is handled by the clinics which are related to the Orthopedic and Rheumatologist. It is usually described as radiculopathy or mono neuropathy which can be caused by the compressive forces which cause the distortion. In the study which was carried out by the American Academy of the Orthopedic Surgeons of CTS described it as a symptomatic compression which is caused on the median nerve at the max level of the wrist. The CTS is the most common form of the entrapment of the median nerve. It then accounts for the $90 \%$ of all the neuropathy entrapment. The entrapment of the median nerve is usually at the level of the carpel tunnel which is in the limitation of the carpel bones and also the carpel ligament. The pressure that is accused decreases the function of the median nerve (MD, 2000).

The CTS is categorized by the motor symptoms, sensory a d also with the channeling of the median nerve. The causes of the CTS which are known include; pregnancy, trauma, hypothyroidism, acromegaly and also arthritis. It is accused by the numbness, pain, tingling in the upper extremes and also working disability. It was wrongly believed that the CTS are just a disorder which is secondary to other major disorders. This might include the hormonal imbalance or the disorders which are neurologically related which are only limited to a certain population and soon becomes a lifestyle in them. Several studies have notified that the CTS can be notified as the occupational disorder. This is so because a lot of jobs require the activity of increasing risk and functions such as gripping. But there are other certain activities which pose a threat to the median nerve for example laptop, mobile phones and video games (Peters, 2016).

Since the world is continuously moving forward and the technological developments are taking place the daily use of gadgets has become a necessity. This is so because this ensures that one can always remain connected to the world and also it gets the work done more easily and fatly. This growing usage has ensured that more dangerous diseases will prevail and CTS also falls under the same category. This is a truth which should be understood by people. There have been studies carried out which show that how the usage of the computer and the mousse can be a threat to the humans and how they have been one of the major reason behind the CTS. These studies also depicted how 
this low work force causes the compression in the median nerve and also lead to the numbness in the hand which can become permanent(MD C. Y.-T., 2016).

CTS are one of the problems which cause tingling in the hand and arm and also cause numbness and pain. This condition can be experienced which the one of the major never that is the median nerve is suppressed from the point it connects on the wrist. The CTS can become very dangerous and worse if the diagnoses and the treatment is done on the time since it becomes complicated. In an early stage the CTS can be avoided using simple measure such as avoiding some certain activities and also by wearing a wrist splint. If the preventions are not taken place hen this can cause severe damage to the brain nerves and also other worsening situations can be faced. Some patients are also recommended with a surgery because their cases are extremely on a dangerous position. The carpel tunnel is situated in the wrist which is about an inch wider. The carpel tunnel is made of the bones which are known as the carpel bones. The connective tissues in the carpel tunnel are known as the carpel ligament. They are extremely strong since they have the ability to stretch and increase themselves in size (Vasiliadis, 2014).

The CTS is one of the syndromes which are related to the nerves in the human. The median nerve is involved is known as the median nerve and it can be studied when the situation is exposed to the vibration. In the general population the frequency of the CTS varies from 1-2\%. The major diagnosis of the CTS is based on the medical history of the person and also the symptoms. But if there is any confusing situation then it is cleared by the electro diagnostic tests. The vascular and the neural problems in the hand result in the pain and numbness. The usual risk factors which are associated with the CTS account for are boring work nature, exertion and stress. Also, longevity of the closed palms and flexures of the shoulders can be one of the major factors of the CTS (Kim, 2013).

There has been a long debate on the issue if the CTS are a work related issue or not. The study which was carried out by Falkner conducted a study on the link between CTS and the work load. It was identified in the study that the CTS is related to the disease of diabetics and to such unhealthy lifestyles where obesity and alcohol intake. But it was discovered that the work related issues were in the bottom of the searches. It was also found out that the major occurrence of the CTS was found out on the work related issues. Some of the jobs which were highlighted in the CTS accounted for the jobs which involved vibrations, laxation and also extension of the wrist of the arms (WenLin Tung, 2010).

It was discovered that the CTS is majorly observed because of the compression of the median nerve in the wrist in the carpel tunnel. The major factors in the CTS are pins, burning sensations, needles and certain numbness in the median nerve. The CTS symptoms usually occur in the early morning or late at the night. Other symptoms which are included account of the weakness in the thumb, dropping of things and feeling of clumsiness in the fingers. CTS play an important role in the field of dentistry. This can be increased because of continuous laxation or some kind of laxation in the wrist (MD J. C., 2000).

The CTS can be linked to several factors such as the psychological, infidel or even work related characteristics. The women who were above the age of 45 , obese, are related to some kind of chronic disease, who also have a history of using more contraceptive pills and are traumatized are more prone to this disease. There are certain doctors who are also facing the similar disease and this is because they ache been practicing for quite a long period of time. This study was supported by other researchers who stated that doctors who have been practicing for more than 10 years have been found with CTS. This is so because such jobs require time management where social interactions are very low (MD J. C., AAEM minimonograph \#26: The electrodiagnosis of carpal tunnel syndrome, 2002).

The CTS can be largely found in the dentists and they can be facing this issue from the period they have been training to the time when they start practicing on their own. This can continue to grow if the right kind of preventive measures are not taken at the right time. This disease can largely affect the neck, spine and the hands of the person. During their study period the students can acquire some kind of habits which are extremely dangerous for them and their occupation. This why there is a need for the strategies which can be ensures the right kind of wellbeing of the person. One of the strategies which should be implemented is to make the students understand that what kind of activities can be contributing to the CTS and how they should be stopped (O'Connor, 2003).

Although facilitating the students with the information about the CTS cannot be enough because they should be properly educated with the information of it. The students should be evaluated on a regular basis and their feedbacks should also be taken. This will ensue that they are developing the right kind of occupational health for their future. This is why a large number of studies have been carried out to ensure that the factors and the drawbacks are highlighted (MD D. C., 2014').

\section{Aims of the study}

- Determine the prevalence of carpal tunnel syndrome among the dentists in Riyadh city.

- Compare between dentist having different quantity of workloads.

- Comparison on the basis of work experience.

\section{Materials and methods}

This is a survey based cross sectional study, which utilized the dentists working in Riyadh city. Survey was designed using Google forms and send to the study participants using the social media and emails. A total of 190 dentists were recruited in this study. The survey included questions related to demographics and symptoms related to carpal tunnel syndrome.

Collected data will be analyzed using SPSS. Descriptive statistics was done including Chi-square test.

\section{Results}

Comparison on the Basis of Work Experience:

\section{Crosstab}

Count 


\begin{tabular}{|c|c|c|c|c|c|}
\hline & & Never heard of it & $\begin{array}{l}\text { Have moderate } \\
\text { information }\end{array}$ & Very & \\
\hline \multirow{4}{*}{ Work Experience } & $1-3 \mathrm{yrs}$ & 44 & 36 & 5 & 85 \\
\hline & $3-6 \mathrm{yrs}$ & 14 & 38 & 11 & 63 \\
\hline & $6-10 \mathrm{yrs}$ & 0 & 29 & 10 & 39 \\
\hline & $10+y r s$ & 0 & 2 & 1 & 3 \\
\hline Total & & 58 & 105 & 27 & 190 \\
\hline
\end{tabular}

P-value: 0.000 .

\begin{tabular}{|c|c|c|c|c|c|c|c|}
\hline \multicolumn{8}{|l|}{$\begin{array}{l}\text { Crosstab } \\
\text { Count }\end{array}$} \\
\hline & & \multicolumn{5}{|c|}{ Pain While Working } & \multirow{2}{*}{ Total } \\
\hline & & No pain at all & Little pain & Moderate pain & Intense pain & Severe pain & \\
\hline \multirow{4}{*}{ Work Experience } & $1-3$ yrs & 33 & 29 & 19 & 4 & 0 & 85 \\
\hline & $3-6$ yrs & 7 & 20 & 35 & 0 & 1 & 63 \\
\hline & $6-10 \mathrm{yrs}$ & 0 & 6 & 26 & 4 & 3 & 39 \\
\hline & $10+\mathrm{yrs}$ & 0 & 0 & 3 & 0 & 0 & 3 \\
\hline Total & & 40 & 55 & 83 & 8 & 4 & 190 \\
\hline
\end{tabular}

P-value: 0.000 .

\begin{tabular}{|c|c|c|c|c|c|c|c|}
\hline \multicolumn{8}{|l|}{$\begin{array}{l}\text { Crosstab } \\
\text { Count }\end{array}$} \\
\hline & & \multicolumn{5}{|c|}{ Pain At Night Time } & \multirow{2}{*}{ Total } \\
\hline & & No pain at all & Little pain & Moderate pain & Intense pain & Severe pain & \\
\hline \multirow{4}{*}{ Work Experience } & $1-3$ yrs & 33 & 28 & 18 & 4 & 1 & 84 \\
\hline & $3-6 \mathrm{yrs}$ & 18 & 14 & 28 & 2 & 1 & 63 \\
\hline & $6-10 \mathrm{yrs}$ & 5 & 2 & 28 & 2 & 2 & 39 \\
\hline & $10+y r s$ & 1 & 1 & 0 & 1 & 0 & 3 \\
\hline Total & & 57 & 45 & 74 & 9 & 4 & 189 \\
\hline \multicolumn{8}{|l|}{ P-value: 0.000.} \\
\hline \multicolumn{8}{|l|}{ Crosstab } \\
\hline \multicolumn{8}{|l|}{ Count } \\
\hline \multicolumn{7}{|c|}{ Pain During Day Time } & \multirow{2}{*}{ Total } \\
\hline & & No pain at all & Little pain & Moderate & Intense pain & Severe pain & \\
\hline \multirow{4}{*}{ Work Experience } & $1-3 \mathrm{yrs}$ & 39 & 23 & 17 & 6 & 0 & 85 \\
\hline & $3-6$ yrs & 11 & 20 & 30 & 1 & 1 & 63 \\
\hline & $6-10 \mathrm{yrs}$ & 1 & 6 & 25 & 4 & 3 & 39 \\
\hline & $10+y r s$ & 0 & 0 & 2 & 1 & 0 & 3 \\
\hline Total & & 51 & 49 & 74 & 12 & 4 & 190 \\
\hline
\end{tabular}

P-value: 0.000 .

\begin{tabular}{|c|c|c|c|c|c|c|c|}
\hline \multicolumn{8}{|l|}{$\begin{array}{l}\text { Crosstab } \\
\text { Count }\end{array}$} \\
\hline & & \multicolumn{5}{|l|}{ Feel Weakness? } & \multirow{2}{*}{ Tota } \\
\hline & & No weakness at all & Little weakness & Moderate weakness & Intense weakness & Severe weakness & \\
\hline \multirow{4}{*}{ Work Experience } & $1-3 \mathrm{yrs}$ & 47 & 20 & 16 & 2 & 0 & 85 \\
\hline & $3-6 \mathrm{yrs}$ & 14 & 22 & 23 & 2 & 1 & 62 \\
\hline & $6-10 \mathrm{yrs}$ & 1 & 7 & 23 & 5 & 3 & 39 \\
\hline & $10+y r s$ & 0 & 0 & 2 & 1 & 0 & 3 \\
\hline Total & & 62 & 49 & 64 & 10 & 4 & 189 \\
\hline
\end{tabular}

P-value: 0.000 .

\section{Crosstab}

Count

\begin{tabular}{|c|c|c|c|c|c|c|c|}
\hline & & $\begin{array}{l}\text { CTS Work Related } \\
\text { Strongly disagree }\end{array}$ & Disagree & Neutral & Agree & Strongly agree & Total \\
\hline \multirow{2}{*}{ Work Experience } & $1-3 \mathrm{yrs}$ & 7 & 6 & 38 & 20 & 13 & 84 \\
\hline & $3-6$ yrs & 1 & 4 & 22 & 11 & 25 & 63 \\
\hline
\end{tabular}




\begin{tabular}{|c|c|c|c|c|c|c|c|}
\hline & $6-10 \mathrm{yrs}$ & 1 & 3 & 8 & 8 & 19 & 39 \\
\hline & $10+y r s$ & 0 & 1 & 0 & 0 & 2 & 3 \\
\hline Total & & 9 & 14 & 68 & 39 & 59 & 189 \\
\hline \multicolumn{8}{|l|}{ P-Value: 0.007.} \\
\hline \multicolumn{8}{|l|}{ Crosstab } \\
\hline \multicolumn{8}{|l|}{ Count } \\
\hline & & \multicolumn{5}{|c|}{ CTS Genetically Linked } & \multirow{2}{*}{ Total } \\
\hline & & Strongly disagree & Disagree & Neutral & Agree & Strongly agree & \\
\hline \multirow{4}{*}{ Work Experience } & $1-3$ yrs & 7 & 22 & 35 & 16 & 5 & 85 \\
\hline & $3-6$ yrs & 1 & 9 & 30 & 15 & 8 & 63 \\
\hline & $6-10 \mathrm{yrs}$ & 0 & 3 & 9 & 11 & 16 & 39 \\
\hline & $10+\mathrm{yrs}$ & 0 & 0 & 0 & 2 & 1 & 3 \\
\hline Total & & 8 & 34 & 74 & 44 & 30 & 190 \\
\hline
\end{tabular}

P-value: 0.000 .

\begin{tabular}{|c|c|c|c|c|c|c|c|}
\hline \multicolumn{8}{|l|}{$\begin{array}{l}\text { Crosstab } \\
\text { Count }\end{array}$} \\
\hline & & \multicolumn{5}{|c|}{ CTS Associated with Diabetes } & \multirow{2}{*}{ Total } \\
\hline & & Strongly disagree & Disagree & Neutral & Agree & Strongly agree & \\
\hline \multirow{4}{*}{ Work Experience } & $1-3 \mathrm{yrs}$ & 5 & 21 & 30 & 19 & 10 & 85 \\
\hline & $3-6 \mathrm{yrs}$ & 1 & 8 & 28 & 14 & 12 & 63 \\
\hline & $6-10 \mathrm{yrs}$ & 2 & 2 & 11 & 8 & 16 & 39 \\
\hline & $10+y r s$ & 0 & 0 & 1 & 0 & 2 & 3 \\
\hline Total & & 8 & 31 & 70 & 41 & 40 & 190 \\
\hline
\end{tabular}

P-value: 0.011 .

\begin{tabular}{|c|c|c|c|c|c|c|c|}
\hline \multicolumn{8}{|l|}{$\begin{array}{l}\text { Crosstab } \\
\text { Count }\end{array}$} \\
\hline & & \multicolumn{5}{|c|}{ CTS Associated With Age } & \multirow{2}{*}{ Total } \\
\hline & & Strongly disagree & Disagree & Neutral & Agree & Strongly agree & \\
\hline \multirow{4}{*}{ Work Experience } & $1-3 \mathrm{yrs}$ & 7 & 10 & 29 & 27 & 10 & 83 \\
\hline & $3-6 \mathrm{yrs}$ & 2 & 6 & 15 & 18 & 22 & 63 \\
\hline & $6-10 \mathrm{yrs}$ & 0 & 2 & 8 & 9 & 20 & 39 \\
\hline & $10+\mathrm{yrs}$ & 0 & 0 & 1 & 1 & 1 & 3 \\
\hline Total & & 9 & 18 & 53 & 55 & 53 & 188 \\
\hline
\end{tabular}

P-value: 0.011.

\begin{tabular}{|c|c|c|c|c|c|c|c|}
\hline \multicolumn{8}{|l|}{$\begin{array}{l}\text { Crosstab } \\
\text { Count }\end{array}$} \\
\hline & & \multicolumn{5}{|l|}{ Need More Info } & \multirow{2}{*}{ Total } \\
\hline & & Strongly disagree & Disagree & Neutral & Agree & Strongly agree & \\
\hline \multirow{4}{*}{ Work Experience } & $1-3 \mathrm{yrs}$ & 8 & 8 & 12 & 25 & 31 & 84 \\
\hline & $3-6 \mathrm{yrs}$ & 2 & 2 & 12 & 11 & 36 & 63 \\
\hline & $6-10 \mathrm{yrs}$ & 0 & 4 & 6 & 4 & 25 & 39 \\
\hline & $10+\mathrm{yrs}$ & 0 & 0 & 1 & 0 & 2 & 3 \\
\hline Total & & 10 & 14 & 31 & 40 & 94 & 189 \\
\hline
\end{tabular}

P-value: 0.054 .

Comparison on the Basis of Daily Patients Exposure:

\begin{tabular}{|c|c|c|c|c|c|}
\hline \multirow{2}{*}{\multicolumn{6}{|c|}{$\begin{array}{l}\text { Crosstab } \\
\text { Count }\end{array}$}} \\
\hline & & & & & \\
\hline & & \multicolumn{4}{|l|}{ Know Carpel Tunnel } \\
\hline \multirow{3}{*}{ Daily Pts Exposure } & $1-5$ patients & 39 & 33 & 5 & 77 \\
\hline & $6-10$ patients & 12 & 36 & 14 & 62 \\
\hline & $11-15$ patients & 5 & 34 & 8 & 47 \\
\hline
\end{tabular}




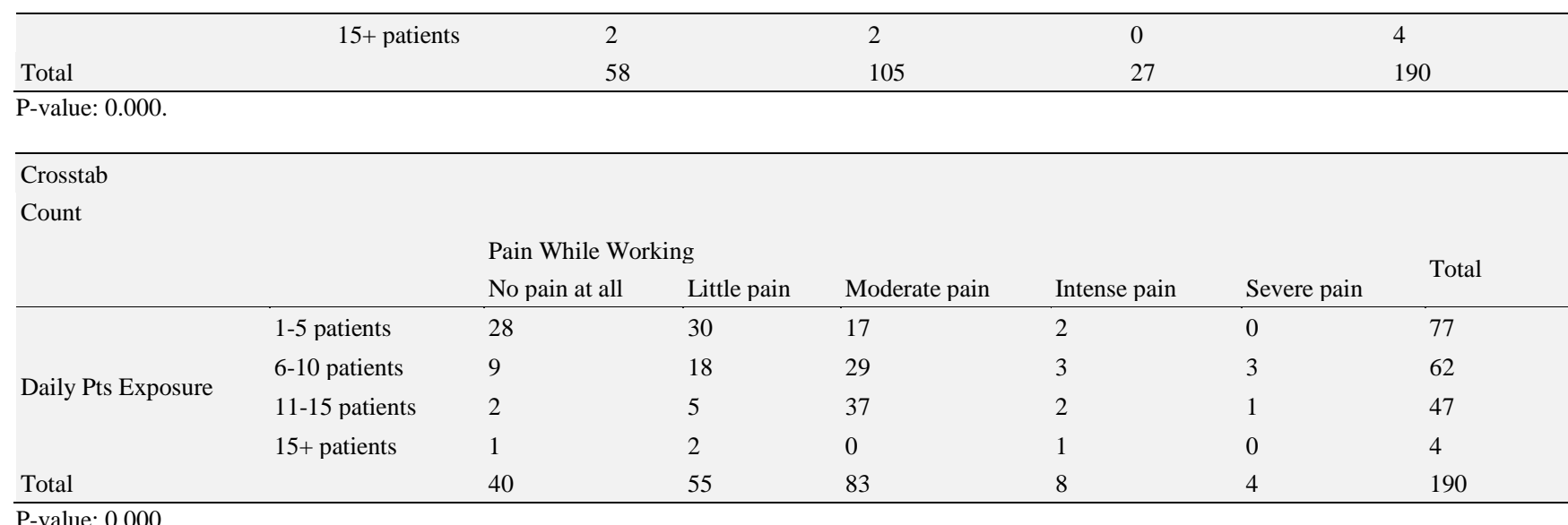

P-value: 0.000

\section{Crosstab}

Count

\begin{tabular}{|c|c|c|c|c|c|c|c|}
\hline & & \multicolumn{5}{|c|}{ Pain At Night Time } & \multirow{2}{*}{ Total } \\
\hline & & No pain at all & Little pain & Moderate pain & Intense pain & Severe pain & \\
\hline \multirow{4}{*}{ Daily Pts Exposure } & $1-5$ patients & 33 & 21 & 17 & 4 & 1 & 76 \\
\hline & 6-10 patients & 16 & 16 & 25 & 2 & 3 & 62 \\
\hline & $11-15$ patients & 6 & 6 & 32 & 3 & 0 & 47 \\
\hline & $15+$ patients & 2 & 2 & 0 & 0 & 0 & 4 \\
\hline Total & & 57 & 45 & 74 & 9 & 4 & 189 \\
\hline
\end{tabular}

P-value: 0.000 .

\begin{tabular}{|c|c|c|c|c|c|c|c|c|}
\hline \multicolumn{9}{|l|}{$\begin{array}{l}\text { Crosstab } \\
\text { Count }\end{array}$} \\
\hline & & \multicolumn{4}{|c|}{ Pain During Day Time } & \multirow[b]{2}{*}{ Intense pain } & \multirow[b]{2}{*}{ Severe pain } & \multirow{2}{*}{ Total } \\
\hline & & \multicolumn{2}{|l|}{ No pain at all } & Little pain & Moderate & & & \\
\hline \multirow{4}{*}{ Daily Pts Exposure } & $1-5$ patients & \multicolumn{2}{|l|}{33} & 25 & 16 & 3 & 0 & 77 \\
\hline & 6-10 patients & 11 & & 18 & 25 & 5 & 3 & 62 \\
\hline & 11-15 patients & \multicolumn{2}{|l|}{5} & 5 & 33 & 3 & 1 & 47 \\
\hline & $15+$ patients & \multicolumn{2}{|l|}{2} & 1 & 0 & 1 & 0 & 4 \\
\hline Total & & \multicolumn{2}{|l|}{51} & 49 & 74 & 12 & 4 & 190 \\
\hline \multicolumn{9}{|l|}{ P-value: 0.000.} \\
\hline Crosstab & & & & & & & & \\
\hline Count & & & & & & & & \\
\hline & & Feel Weakness & & & & & & \\
\hline & & $\begin{array}{l}\text { No weakness at } \\
\text { all }\end{array}$ & Little & weakness & $\begin{array}{l}\text { Moderate } \\
\text { weakness }\end{array}$ & Intense weakness & Severe weakness & Total \\
\hline & $1-5$ patients & 41 & 20 & & 13 & 3 & 0 & 77 \\
\hline Daily Pts Fxnosure & 6-10 patients & 14 & 18 & & 23 & 4 & 3 & 62 \\
\hline Dany & $11-15$ patients & 6 & 9 & & 27 & 3 & 1 & 46 \\
\hline & $15+$ patients & 1 & 2 & & 1 & 0 & 0 & 4 \\
\hline Total & & 62 & 49 & & 64 & 10 & 4 & 189 \\
\hline P-value: 0.000. & & & & & & & & \\
\hline Crosstab & & & & & & & & \\
\hline Count & & & & & & & & \\
\hline & & $\begin{array}{l}\text { CTS Work R } \\
\text { Strongly dis }\end{array}$ & $\begin{array}{l}\text { elated } \\
\text { agree }\end{array}$ & Disagree & Neutral & Agree & ongly agree & Total \\
\hline & $1-5$ patients & 7 & & 5 & 32 & 20 & & 77 \\
\hline Daily Pts Exposure & 6-10 patients & 0 & & 5 & 18 & 14 & & 61 \\
\hline 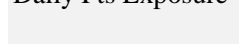 & 11-15 patients & 1 & & 4 & 15 & 22 & & 47 \\
\hline & $15+$ patients & 1 & & 0 & 3 & 0 & & 4 \\
\hline Total & & 9 & & 14 & 68 & 39 & & 189 \\
\hline
\end{tabular}

P-value: 0.003 


\begin{tabular}{|c|c|c|c|c|c|c|c|}
\hline \multicolumn{8}{|l|}{$\begin{array}{l}\text { Crosstab } \\
\text { Count }\end{array}$} \\
\hline & & \multicolumn{5}{|c|}{ CTS Genetically Linked } & \multirow{2}{*}{ Tota } \\
\hline & & Strongly disagree & Disagree & Neutral & Agree & Strongly agree & \\
\hline \multirow{4}{*}{ Daily Pts Exposure } & 1-5 patients & 6 & 20 & 39 & 10 & 2 & 77 \\
\hline & 6-10 patients & 1 & 8 & 21 & 20 & 12 & 62 \\
\hline & 11-15 patients & 0 & 5 & 13 & 13 & 16 & 47 \\
\hline & $15+$ patients & 1 & 1 & 1 & 1 & 0 & 4 \\
\hline Total & & 8 & 34 & 74 & 44 & 30 & 190 \\
\hline
\end{tabular}

P-value: 0.000 .

\begin{tabular}{|c|c|c|c|c|c|c|c|}
\hline \multicolumn{8}{|l|}{ Crosstab } \\
\hline & & \multicolumn{5}{|c|}{ CTS Associated Diabetes } & \multirow{2}{*}{ Total } \\
\hline & & Strongly disagree & Disagree & Neutral & Agree & Strongly agree & \\
\hline \multirow{4}{*}{ Daily Pts Exposure } & $1-5$ patients & 6 & 20 & 28 & 16 & 7 & 77 \\
\hline & 6-10 patients & 1 & 9 & 25 & 11 & 16 & 62 \\
\hline & $11-15$ patients & 1 & 1 & 17 & 11 & 17 & 47 \\
\hline & $15+$ patients & 0 & 1 & 0 & 3 & 0 & 4 \\
\hline Total & & 8 & 31 & 70 & 41 & 40 & 190 \\
\hline
\end{tabular}

P-value: 0.001 .

\begin{tabular}{|c|c|c|c|c|c|c|c|}
\hline \multicolumn{8}{|l|}{$\begin{array}{l}\text { Crosstab } \\
\text { Count }\end{array}$} \\
\hline & & CTS With Age & & & & & Totol \\
\hline \multirow{5}{*}{ Daily Pts Exposure } & & & & & $18+0$ & & \\
\hline & $1-5$ patients & 7 & 12 & 21 & 27 & 9 & 76 \\
\hline & 6-10 patients & 0 & 4 & 18 & 16 & 23 & 61 \\
\hline & 11-15 patients & 1 & 1 & 13 & 11 & 21 & 47 \\
\hline & $15+$ patients & 1 & 1 & 1 & 1 & 0 & 4 \\
\hline Total & & 9 & 18 & 53 & 55 & 53 & 188 \\
\hline
\end{tabular}

P-value: 0.001

\begin{tabular}{|c|c|c|c|c|c|c|c|}
\hline \multicolumn{8}{|l|}{$\begin{array}{l}\text { Crosstab } \\
\text { Count }\end{array}$} \\
\hline & & Need More Info & & & & & Totol \\
\hline \multirow{4}{*}{ Daily Pts Exposure } & $1-5$ patients & 6 & 8 & 10 & 26 & 27 & 77 \\
\hline & 6-10 patients & 2 & 2 & 13 & 8 & 36 & 61 \\
\hline & $11-15$ patients & 1 & 4 & 8 & 5 & 29 & 47 \\
\hline & $15+$ patients & 1 & 0 & 0 & 1 & 2 & 4 \\
\hline Total & & 10 & 14 & 31 & 40 & 94 & 189 \\
\hline
\end{tabular}

P-value: 0.011.

\section{Discussion}

This study aimed to determine the prevalence of carpel tunnel syndrome (CTS) among the dental practitioners in Riyadh city. We discovered statistically significant comparisons among various sub-groups, including work experience and daily patient exposure. It was obvious from the results that dentists with more experience had better knowledge about CTS. Similarly, dental professionals with more work experience exhibited more pain while working. It can also be noted from the results that there were only 3 dentists in this study having a work experience of 10 or more years, therefore the findings cannot be accurately compared with the other groups. However, we have presented the overall results hence the comparison.

Participants having more experience reported higher prevalence of muscle weakness and pain during night time. Overall majority of the participants believed that CTS is work related as well as genetically linked. Similar findings were reported when inquired about the association of CTS with endocrine related diseases such as diabetes and thyroid disease. Participants with more experience tend to have better knowledge regarding this issue as well as the association of CTS with increasing age.

We also compared the responses of participants on the basis of daily patient exposure. Dentists with least patient exposure exhibited poor knowledge about CTS. However, subjects with the most patient's exposure reported prevalence of pain in hands while working. Similarly, participants having less daily exposure of patients experienced no pain while working, at night time and even day time. Dentists with more 
patients' exposure experienced moderate to intense weakness in their hands. Knowledge about CTS and its association with factors such as genetics, diabetes, thyroid disease and ageing was seen higher in participants with more patients' exposure.

Overall, the knowledge regarding CTS seems to be satisfactory with significant differences in the levels among various groups of study participants. This knowledge was seen well among the experienced dental practitioners. There is a need of creating awareness among the dental professionals of all demographics. One of the limitations to this study was the small sample size. In future, we aim to expand the scope of this study and measure the CTS knowledge and prevalence with much more expansive results.

\section{Conclusions}

- CTS seem to be of higher problem among dentists with more clinical experience.

- CTS knowledge among dentists with greater patients' exposure was higher.

- Awareness of CTS needs to be incorporated in all demographics of dental professionals

\section{References}

[1] Kim, D. H. (2013). Pressure-morphology relationship of a released carpal tunnel. Journal of Orthopaedic Research, 616-620. https://doi.org/10.1002/jor.22271.

[2] MD, C. Y.-T. (2016). Review of Ultrasonography in the Diagnosis of Carpal Tunnel Syndrome and a Proposed Scanning Protocol. Journal of Ultrasound, 2311-2324. https://doi.org/10.7863/ultra.15.12014.

[3] MD, D. C. (2014). Literature review of the usefulness of nerve conduction studies and electromyography for the evaluation of patients with carpal tunnel syndrome. Muscle \& Nerve, 1392-1414.

[4] MD, J. C. (2000). AAEE minimonograph \#26: The electrodiagnosis of carpal tunnel syndrome. Muscle and Nerve, 99-113.

[5] MD, J. C. (2002). AAEM minimonograph \#26: The electrodiagnosis of carpal tunnel syndrome. Muscle \& Nerve, 1477-1486.

[6] MD, J. E. (2000). Surgical treatment of common entrapment neuropathies in the upper limbs. Muscle and Nerve, $1160-1174$. https://doi.org/10.1002/1097-4598(200008)23:8<1160::AID-MUS2>3.0.CO;2-4.

[7] O'Connor, D. (2003). Non-surgical treatment (other than steroid injection) for carpal tunnel syndrome. The Cochrane Library, 124-135. https://doi.org/10.1002/14651858.CD003219.

[8] Peters, S. (2016). Rehabilitation following carpal tunnel release. The Cochrane Library, 34-56. https://doi.org/10.1002/14651858.CD004158.pub3.

[9] Vasiliadis, H. S. (2014). Endoscopic release for carpal tunnel syndrome. The Cochrane Library, 89-97. https://doi.org/10.1002/14651858.CD008265.pub2.

[10] Wen-Lin Tung. (2010). Comparative study of carpal tunnel compliance in the human, dog, rabbit, and rat. Journal of Orthopaedic Research, 652656. https://doi.org/10.1002/jor.21037. 